Review

\title{
How Efficient Is My (Medicinal) Chemistry?
}

\author{
Jean Jacques Vanden Eynde \\ Laboratory of Organic Chemistry, University of Mons-UMONS, Place du Parc 23, Mons B-7000, Belgium; \\ jean-jacques.vandeneynde@ex.umons.ac.be; Tel.: + 32-2-355-8161 \\ Academic Editor: Derek J. McPhee \\ Received: 27 January 2016; Accepted: 10 May 2016; Published: 16 May 2016
}

\begin{abstract}
Greening" a chemical transformation is not about only changing the nature of a solvent or decreasing the reaction temperature. There are metrics enabling a critical quantification of the efficiency of an experimental protocol. Some of them are applied to different sequences for the preparation of paracetamol in order to understand their performance parameters and elucidate pathways for improvement.
\end{abstract}

Keywords: atom economy; ecoscale; E factor; green chemistry; life cycle analysis; paracetamol; reaction mass efficiency; stoichiometric factor; waste; yield

\section{Introduction}

As largely emphasized during the recent United Nations Conference on Climate Change (COP21 [1]) held in Paris (France), nowadays there is an increasing awareness and urgent necessity of limiting, as far as possible, any source of pollution and accumulation of waste. Consequently, the environmental legislation becomes ever more severe in order to respond to the public pressure and to the demands of green movements. On the other hand, economical constraints lead chemical industries to improve their processes, to reduce the cost of their production, and to accelerate the discovery of novel commercial products. Faced with that situation, scientists have to explore new ways to perform chemical transformations and the disclosure of innovative experimental procedures emerges as a fascinating and inescapable challenge. In that sense, the past few years have been particularly fruitful with the intensive use of supported reagents as well as with the introduction of ultrasound generators and microwave ovens in research laboratories. Pharmaceutical companies have benefited in addition from the development of combinatorial chemistry, which has been accompanied by an exploding renewal of interest for solid phase synthesis. Besides those methodologies, a novel concept arose at the end of the 20th century under the name of Green Chemistry [2]. In many papers you can read that environmentally friendly protocols have been developed to improve known reactions or to access original compounds. However, are those protocols as green as claimed? Do they really follow the principles of Green Chemistry? Are they characterized by favorable metrics, having in mind that any amount of a substance that is not incorporated in the final product will become a waste if it cannot directly be reused? This year, the ACS Green Chemistry Institute will organize, in Portland (OR, USA), the 20th Annual Green Chemistry and Engineering Conference [3]. This is a pretext and an opportunity to remind us, in this review, of some now familiar but useful tools for a critical evaluation of the performance and environmental impact of a chemical reaction.

\section{The Twelve Principles of Green Chemistry and the Principles of Green Engineering}

The publication of the Twelve Principles of Green Chemistry by Anastas and Warner in 1998 [2] has undoubtedly been the most efficient tool for the development of chemical procedures aiming to limit the amount of waste and to protect the environment. Extrapolation of those concepts to the industrial world can be found in the Twelve Principles of Green Engineering, disclosed in 2003 by 
Anastas and Zimmerman [4] and in the Nine Principles of Green Engineering, which are described in the Sandestin Declaration [5]. The three lists are reported in Figures 1-3. Mention could also be made of twelve more principles of Green Chemistry added in 2001 by Winterton [6] and Six Principles of Sustainability established by engineering institutions in the United Kingdom [7].

\section{The Twelve Principles of Green Chemistry \\ by P.T. Anastas and J.C. Warner}

\section{Prevention}

It is better to prevent waste than to treat or clean up waste after it is formed.

2. Atom economy

Synthetic methods should be designed to maximize incorporation of all materials used in the process into the final products.

3. Less hazardous chemical synthesis

Wherever practicable, synthetic methods should be designed to use and generate substances that possess little or no toxicity.

4. Designing safer chemicals

Chemical products should be designed to effect their desired function while minimizing their toxicity.

\section{Safer solvents and auxiliaries}

The use of auxiliary substances (e.g. solvents or separation agents) should be made unnecessary whenever possible and innocuous when used.

\section{Design for energy efficiency}

Energy requirements of chemical processes should be recognized for their environmental and economic impacts and should be minimized. If possible, synthetic methods should be conducted at ambient temperature and pressure.

\section{Use of renewable feedstocks}

A raw material or feedstock should be renewable rather than depleting whenever technically and economically practicable.

\section{Reduce derivatives}

Unnecessary derivatization (use of blocking groups, protection-deprotection, etc) should be minimized or avoided if possible, because such steps require additional reagents and can generate waste.

9. Catalysis

Catalytic reagents (as selective as possible) are superior to stoichiometric reagents.

\section{Design for degradation}

Chemical products should be designed so that at the end of their function they break down into innocuous degradation products and do not persist in the environment.

11. Real-time analysis for pollution prevention

Analytical methodologies need to be further developed to allow real-time, in process monitoring and control prior to the formation of hazardous substances.

\section{Inherently safer chemistry for accident prevention}

Substances and the form of a substance used in a chemical process should be chosen to minimize the potential of chemical accidents, including releases, explosions, and fires.

Figure 1. The twelve principles of Green Chemistry [2]. 


\section{The Twelve Principles of Green Engineering}

\section{by P.T. Anastas and J.B. Zimmerman}

\section{Inherent rather than circumstantial}

Designers need to strive to ensure that all materials and energy inputs and outputs are as inherently nonhazardous as possible

\section{Prevention instead of treatment}

It is better to prevent waste than to treat or clean up waste after it is formed.

\section{Design for separation}

Separation and purification operations should be designed to minimize energy consumption and materials use.

\section{Maximize efficiency}

Products, processes, and systems should be designed to maximize mass, energy, space, and time efficiency.

\section{Output-pulled versus input-pushed}

Products, processes, and systems should be output-pulled rather than input-pushed through the use of energy and materials.

\section{Conserve complexity}

Embedded entropy and complexity must be viewed as an investment when making design choices on recycle, reuse, or beneficial disposition.

\section{Durability rather than immortality}

Targeted durability, not immortality, should be a design goal.

\section{Meet need, minimize excess}

Design for unnecessary capacity or capability (that is "one size fits all") should be considered a design flaw.

\section{Minimize material diversity}

Material diversity in multicomponent products should be minimized to promote disassembly and value retention.

10. Integrate material and energy flows

Design of products, processes, and systems must include integration and interconnectivity with available energy and materials flows.

\section{Design for commercial "afterlife"}

Design of products, processes, and systems should be designed for performance in a commercial "afterlife".

\section{Renewable rather than depleting}

Material and energy inputs should be renewable rather than depleting.

Figure 2. The twelve principles of Green Engineering [4]. 


\section{The Nine Principles of Green Engineering}

In the Sandestin Declaration

1. Engineer processes and products holistically, use systems analysis, and integrate environmental impact assessment tools.

2. Conserve and improve natural ecosystems while protecting human health and well-being.

3. Use life-cycle thinking in all engineering activities.

4. Ensure that all material and energy inputs and outputs are as inherently safe and benign as possible.

5. Minimize depletion of natural resources.

6. Strive to prevent waste.

7. Develop and apply engineering solutions, while being cognizant of local geography, aspirations, and cultures.

8. Create engineering solutions beyond current or dominant technologies, improve, innovate, and invent (technologies) to achieve sustainability.

9. Actively engage communities and stakeholders in development of engineering solutions.

Figure 3. The Sandestin declaration [3].

\section{Some Synthetic Routes to Paracetamol}

Paracetamol (acetaminophen, $\mathrm{N}$-(4-hydroxyphenyl)acetamide, $\mathbf{5}$ in Figure 4) is a well-known analgesic that can be prepared by different synthetic routes from phenol (1). The most usual protocol [8-11] starts by a nitration reaction (Figure 4). After separation of the para isomer from the ortho isomer, 4-nitrophenol (2) is reduced into 4-aminophenol (4). The latter is finally $\mathrm{N}$-acetylated, most often by treatment with acetic anhydride (Route 1) but sometimes using acetyl chloride (Route 2). Hoechst-Celanese [12,13] has proposed a quite different approach (Route 3). It involves acetylation of phenol by action of acetic acid catalyzed by HF. Reaction of $4^{\prime}$-hydroxyacetophenone (6) with hydroxylamine yields the corresponding oxime (7) that is converted into paracetamol by an acid-catalyzed Beckmann rearrangement.

\section{Route 1}

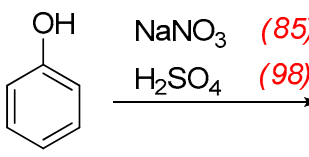

(94)

$\mathrm{NaBH}_{4}$ (38)

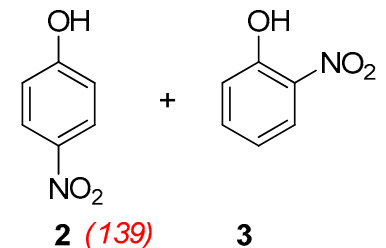

$2(139) \quad 3$<smiles>Nc1ccc(O)cc1</smiles><smiles>CC(=O)OC(C)=O</smiles><smiles>CC(=O)Nc1ccc(O)cc1</smiles>

4 (109)
5 (151)

Figure 4. Cont. 


\section{Route 2}
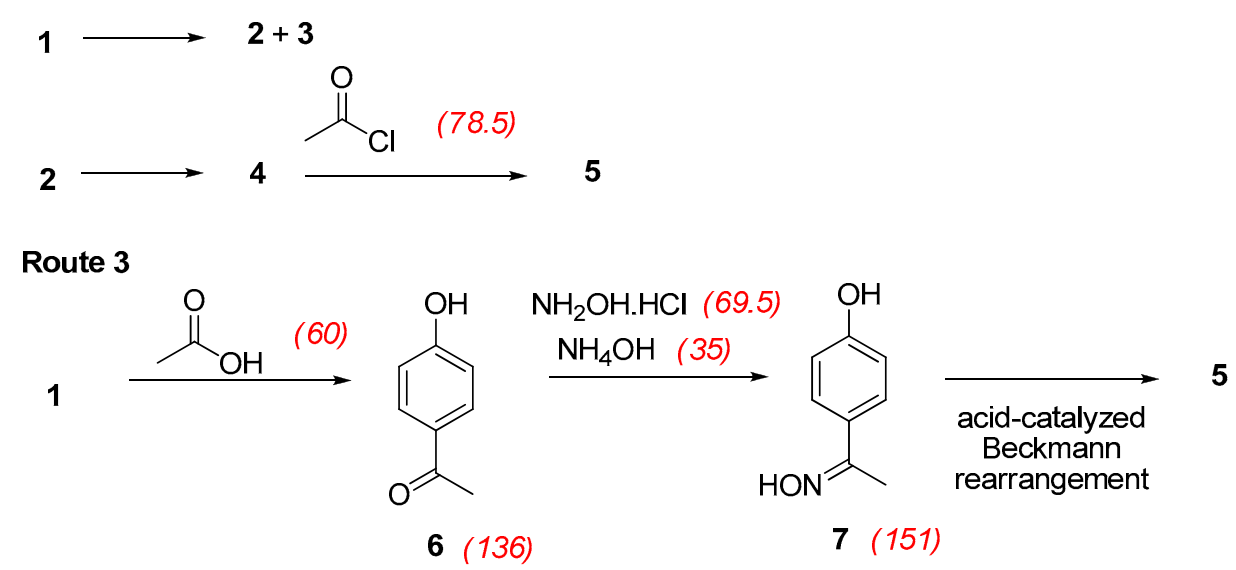

Figure 4. Some synthetic routes for the preparation of paracetamol (molecular weights of reactants and products are indicated in red and in brackets).

The following experimental procedures will be considered in this review. They have been adapted so that each route starts from $100 \mathrm{mmol}$ of phenol and the total amount of an isolated product is systematically engaged in the subsequent step. A particular attention is dedicated to the $\mathrm{N}$-acetylation of 4-aminophenol because different protocols have been reported in the literature, thus enabling a comparison of their respective efficiencies.

\subsection{Nitration of Phenol}

Place a three-necked round bottom flask in an ice water bath and place a thermometer into one of the necks. Place $15.00 \mathrm{~g}$ of sodium nitrate into the flask, add $40 \mathrm{~mL}$ of water and stir. Cautiously add concentrated sulfuric acid $(13.6 \mathrm{~mL} ; 25.00 \mathrm{~g})$ to the stirred solution. Slowly add solid phenol $(9.40 \mathrm{~g}$, $100 \mathrm{mmol}$ ) at such a rate that the temperature of the solution does not rise above $20^{\circ} \mathrm{C}$ (about a half a spatula at a time over about $20 \mathrm{~min}$ ) and then stir, preferably with a magnetic stirrer, for $2 \mathrm{~h}$. Remove the thermometer. Decant off the supernatant liquid and add water $(25-30 \mathrm{~mL})$ to the residue. Put a dropping funnel into one of the necks and a stillhead and condenser into another. Insert a stopper in the third. Heat the mixture, and distil off one of the components with the steam. At the same time, add water to the mixture through the dropping funnel at a similar rate. Stop the distillation once the product has stopped coming over, and then filter the distillate to give crystals of the 2-nitrophenol isomer ( $4.17 \mathrm{~g} ; 30 \mathrm{mmol}$ ) in 30\% yield following [9]. Cool the residual solution in the distillation flask, then filter off the other solid isomer (4-nitrophenol; $5.14 \mathrm{~g} ; 37 \mathrm{mmol}$ ) in 37\% yield following [9] and recrystallize it from $0.5 \mathrm{M}$ hydrochloric acid [8].

\subsection{Reduction of 4-Nitrophenol}

Place $51.4 \mathrm{~mL}$ ( $51.4 \mathrm{mmol})$ of $1 \mathrm{M}$ sodium hydroxide in a conical flask. Add $2.88 \mathrm{~g}(76 \mathrm{mmol})$ of sodium borohydride, followed by $50 \mathrm{mg}$ of palladium on charcoal (5\% or $10 \%)$. Cool in ice to approximately $13^{\circ} \mathrm{C}$. Add $5.14 \mathrm{~g}(37 \mathrm{mmol})$ of 4-nitrophenol in very small portions (half a microspatula at a time) over $30 \mathrm{~min}$. Make sure the temperature is kept between $13-17^{\circ} \mathrm{C}$ during the addition. After the addition is complete, the mixture should be stirred for a further $15 \mathrm{~min}$ and acidified with $2 \mathrm{M}$ hydrochloric acid (about $87 \mathrm{~mL}$ ). Filter the mixture to remove catalyst and adjust the filtrate to $\mathrm{pH} 7-8$ by carefully adding solid sodium hydrogenocarbonate a little at a time. Filter off the precipitate and wash with a little cold water to give 4-aminophenol (2.98 g; $27 \mathrm{mmol} ; 74 \%)$ after drying [8]. 


\subsection{Acetylation of 4-Aminophenol}

\subsubsection{With Diluted Acetic Anhydride}

Place $2.98 \mathrm{~g}$ ( $27 \mathrm{mmol})$ of 4 -aminophenol and $27 \mathrm{~mL}$ of distilled water in a $100 \mathrm{~mL}$ conical flask and stir briskly at room temperature in order to suspend the solid in the water. In a fume cupboard, add $3.49 \mathrm{~g} \mathrm{(} 34 \mathrm{mmol})$ of acetic anhydride to the stirred suspension and gently shake to mix. The solid will dissolve after about $30 \mathrm{~s}$. Continue shaking and a precipitate will form after $2 \mathrm{~min}$. After $10 \mathrm{~min}$, the solid should be filtered off under suction, washed with a little cold water and dried $(2.47 \mathrm{~g} ; 16 \mathrm{mmol}$; $60 \%$ ). The product may be purified by crystallization from distilled water [8].

\subsubsection{With Pure Acetic Anhydride in the Presence of a Catalyst}

Mix acetic anhydride $(7.4 \mathrm{~mL}, 7.99 \mathrm{~g}, 78 \mathrm{mmol})$, 4-aminophenol (2.98 g, $27 \mathrm{mmol})$, and $\mathrm{H}_{14}\left[\mathrm{NaP}_{5} \mathrm{~W}_{30} \mathrm{O}_{110}\right](0.02 \mathrm{~g})$ and stir at room temperature for 15 minutes. At the end of the reaction, dilute the mixture with water $(74 \mathrm{~mL})$ and the crude product precipitates by cooling in an ice bath. Yield: 91\% (3.77 g, $25 \mathrm{mmol})$ [10].

\subsubsection{With Acetic Anhydride under Solvent-Free and Catalyst-Free Conditions}

Transfer $27 \mathrm{mmol}$ (2.98 g) of $98 \%$ pure 4-aminophenol and $27 \mathrm{mmol}(2.79 \mathrm{~g})$ of $99 \%$ pure acetic anhydride to a rotary stainless steel ball mill equipped with an exhaust and a scrubber system. Add a slight excess amount $(0.03 \mathrm{~g})$ of acetic anhydride to this mixture. First mix gently and then grind the mixture to about $10 \mu \mathrm{m}$ particle size. Yield: $3.99 \mathrm{~g}, 26 \mathrm{mmol}, 97 \%$ [11].

\subsubsection{With Acetic Chloride under Solvent-Free and Catalyst-Free Conditions}

Transfer $27 \mathrm{mmol}$ (2.98 g) of 98\% pure 4-aminophenol and $27 \mathrm{mmol}(2.14 \mathrm{~g})$ of $99 \%$ pure acetyl chloride to a rotary stainless steel ball mill equipped with an exhaust and a scrubber system. Add a slight excess amount $(0.03 \mathrm{~g})$ of acetyl chloride to this mixture. First mix gently then grind the mixture to about $10 \mu \mathrm{m}$ particle size. Yield: $4.10 \mathrm{~g}, 26$ mmoles, $99 \%$ [11].

\subsection{Acetylation of Phenol}

Charge phenol $(9.40 \mathrm{~g}, 100 \mathrm{mmol})$ and acetic acid $(12.00 \mathrm{~g}, 200 \mathrm{~mol})$ to a $300 \mathrm{~mL}$ Hastelloy C autoclave at room temperature. Evacuate and cool the reactor to $-20^{\circ} \mathrm{C}$. $\mathrm{HF}(100 \mathrm{~g}, 5 \mathrm{~mol})$ and then transfer it into the reactor. Heat the reactor to $80^{\circ} \mathrm{C}$ and maintain for $1 \mathrm{~h}$ at reaction temperature. At the end of the reaction, cool the reactor to $20^{\circ} \mathrm{C}$ and vent the excess $\mathrm{HF}$ to a $\mathrm{KOH}$ scrubber. Add Ethyl acetate to the contents of the reactor. Neutralize the mixture with $45 \%$ aqueous $\mathrm{KOH}$. Separate the resulting organic phase, dry it over $\mathrm{MgSO}_{4}$ and allow it to evaporate to afford a yellow solid that contains $13.10 \mathrm{~g}$ (96 mmol, 96\%) of $4^{\prime}$-hydroxyacetophenone [12].

\subsection{Formation of the Oxime of $4^{\prime}-H y d r o x y a c e t o p h e n o n e$}

Prepar a solution by adding $13.10 \mathrm{~g}(96 \mathrm{mmol})$ of $4^{\prime}$-hydroxyacetophenone, $7.30 \mathrm{~g}(105 \mathrm{mmol})$ of hydroxylamine hydrochloride, and $9.60 \mathrm{~g}$ of water to $38.5 \mathrm{~mL}$ of ethanol. To the solution, add $4.80 \mathrm{~g}$ of $30 \%$ ammonium hydroxide, and then heat at reflux for $2 \mathrm{~h}$. Remove the ethanol in a rotary evaporator to yield a yellow oil. The extractive work-up affords $14.50 \mathrm{~g}(96 \mathrm{mmol}, 99 \%)$ of $4^{\prime}$-hydroxyacetophenone oxime [12].

\subsection{Formation of Paracetamol by an Acid-Catalyzed Beckmann Rearrangement}

Heat a solution of $14.50 \mathrm{~g}$ (96 mmol) of $4^{\prime}$-hydroxyacetophenone oxime and $109.10 \mathrm{~g}$ of trifluoroacetic acid at reflux under a nitrogen atmosphere. Remove the trifluoroacetic acid in a rotary evaporator to afford $21.40 \mathrm{~g}$ of oil, and then dissolve the oil in $100 \mathrm{~mL}$ of water. Cool to $0{ }^{\circ} \mathrm{C}$ 
for $0.5 \mathrm{~h}$, until crystallization occurs. Filtrate and dry the crystals to yield $10.30 \mathrm{~g}(68 \mathrm{mmol}, 71 \%)$ of paracetamol [12].

\section{Mass Balances}

When we perform a chemical reaction, we have to follow a chemical equation and it will immediately indicate the minimum amount of waste we can expect from the experimental process. Indeed, any material that will not enter in the composition of the final product will constitute a waste in one way or another. That concerns reactants and product(s) only. Some associated metrics are atom economy, yield, reaction mass efficiency as defined by Curzons, and stoichiometric factor. In a further step of the evaluation of the environmental impact of a chemical transformation, solvents and any substance used as auxiliary or in the work-up procedure can also be considered. In that case, global reaction efficiency, effective mass yield, process mass intensity, and E-factor will be considered.

\subsection{When Reactants and Product(s) Only Are Considered}

\subsubsection{Atom Economy: A Theoretical Value}

Atom Economy (AE) is defined $[14,15]$ as "the molecular weight of the isolated product divided by the sum of the molecular weights of the reactants", the result being expressed in \%:

$$
\mathrm{AE}=\left(\mathrm{MW}_{\text {isolated product }} / \sum \mathrm{MW}_{\text {reactants }}\right) \times 100
$$

In the case of preparation of paracetamol following Route 1, as described in Figure 4, we have:

$$
\mathrm{AE}=[151 /(94+98+85+38+102)] \times 100=36 \%
$$

where 151 is the molecular weight of paracetamol and 94, 98, 85, 38, and 102 are the molecular weights of phenol, sulfuric acid, sodium nitrate, sodium borohydride, and acetic anhydride, respectively.

That means that in an ideal process, $64 \%$ of the atomic mass of the engaged reactants will constitute waste. This is a purely theoretical minimum value that cannot be modified except when we change the balanced chemical equations. Thus, by replacing acetic anhydride with acetyl chloride (molecular weight: 78.5 ) as the acetylating agent (Route 2), the atom economy is insignificantly increased by $2 \%$ :

$$
\mathrm{AE}=[151 /(94+98+85+38+78.5)] \times 100=38 \%
$$

However, if the synthetic sequence is totally modified, as in the Hoechst-Celanese procedure (Route 3), then the atom economy rises to:

$$
\mathrm{AE}=[151 /(94+60+69.5+40)] \times 100=58 \%
$$

where 94, 60, 69.5, and 40 represent the molecular weights of phenol, acetic acid, hydroxylamine hydrochloride, and sodium hydroxide, respectively, the other substances being used as catalysts. Catalysts are not present in the AE calculation because their atomic material is not consumed, but instead regenerated (at least theoretically), during the chemical process. The favorable increase of the atom economy in this procedure is associated with the facts that: (i) acetic acid (and not acetic anhydride, which has a higher molecular weight) is used for acetylation of phenol; and (ii) conversion of the oxime 7 into the amide 5 is a rearrangement reaction involving catalysts only. Addition and pericyclic reactions are other privileged chemical transformations contributing to a favorable atom economy.

Atom economy values calculated for protocols reported in Sections 3.1-3.6 are gathered in Table 1.

\subsubsection{Yield: A Realistic Experimental Value}

Yield is certainly one of the best known and most critical value associated with an individual chemical transformation. It reflects the efficiency of the process and thus the effective amount of waste created from the reactants. Yield, expressed in percent, is defined by: 


$$
\begin{gathered}
\text { Yield }=[\text { Obtained number of mole }(\mathrm{s}) \text { of the desired product/Theoretical maximum } \\
\text { number of mole }(\mathrm{s}) \text { that can be obtained from the limiting reactant }] \times 100
\end{gathered}
$$

Let us first consider the nitration of phenol $(0.100 \mathrm{~mol})$ as described in Section 3.1. 4-Nitrophenol $(0.037 \mathrm{~mol})$ was obtained in

$$
\text { Yield }=(0.037 / 0.100) \times 100=37 \%
$$

That is a modest value, but it can be expected that unreacted reagents can be recovered and recycled in further runs. However, this will be possible only if those unreacted reagents were not consumed in unwanted transformations. At that point, the notions of selectivity and conversion are introduced. Following the concerned protocol, nitration of phenol is not a selective reaction because in addition to 4-nitrophenol, the compound expected and required for the synthesis of paracetamol, 2-nitrophenol was also obtained. Thus, from the starting $100 \mathrm{mmol}$ of phenol, $67 \mathrm{mmol}$ have been converted: $37 \mathrm{mmol}$ were transformed into the expected product and $30 \mathrm{mmol}$ were "lost" by formation of the ortho isomer. There are only $33 \mathrm{mmol}$ of unreacted starting phenol left. They have not been recycled by the authors [8].

In a multistep synthesis, the overall yield is obtained by multiplying yields calculated for each individual step. For the preparation of paracetamol following Route 1 (Figure 4) and acetylation with diluted acetic anhydride (Section 3.3.1), paracetamol was obtained in an overall yield of:

$$
\text { Overall Yield }=(0.37 \times 0.74 \times 0.60) \times 100=16 \%
$$

What is, in practice, considered as a (very) low yield. However, yields are values depending on the experimental conditions (and on the skills of the chemist!). That explains why various protocols (Sections 3.3.1-3.3.3) describing the $N$-acetylation step of 4-aminophenol with acetic anhydride furnished the final amide in different yields, as indicated in Table 1.

When Route 2 is considered (acetylation with acetyl chloride, Section 3.3.4), the overall yield slightly increases to:

$$
\text { Overall Yield }=(0.37 \times 0.74 \times 0.99) \times 100=27 \%
$$

On the other hand, the Hoechst-Celanese synthetic pathway proposed in reference [12] emerges as a highly more favorable procedure because the overall yield rises to:

$$
\text { Overall Yield }=(0.96 \times 0.99 \times 0.71) \times 100=68 \%
$$

\subsubsection{Reaction Mass Efficiency Following Curzons}

Yields are calculated on the basis of the number of moles of the limiting reactant. In 2001, Curzons et al. [16], researchers at GlaxoSmithKline, defined the concept of "reaction mass efficiency" $\left(\mathrm{RME}_{\text {Curzons }}\right)$ as the ratio between the isolated weight of the final product and the sum of the weights of the reactants:

$\mathrm{RME}_{\text {Curzons }}$ in $\%=$ (isolated weight of the desired product/sum of weights of the reactants $) \times 100$

A value of 100 characterizes an ideal process.

For the nitration of phenol, we can calculate:

$$
\operatorname{RME}_{\text {Curzons }}=[5.14 /(9.40+15+25)] \times 100=10 \%
$$

where 5.14 is the weight (in g) of 4-nitrophenol and 9.40, 15, and 25 are the weights (in g) of phenol, sodium nitrate, and sulfuric acid, respectively. The value means that $90 \%$ of the weights of the reactants 
used in the experiment are not inserted in the product (4-nitrophenol) and considered as waste in the

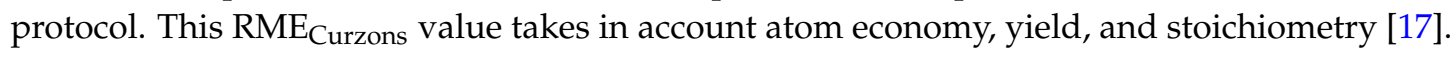

In a multistep synthesis, the calculation of $\mathrm{RME}_{\text {Curzons }}$ requires the assumption that the entire amount of a product obtained in a reaction is engaged in the subsequent step. Therefore, we find for the overall preparation of paracetamol

- Following Route 1 and acetylation with diluted acetic anhydride

$$
\text { overall } \mathrm{RME}_{\text {Curzons }}=[2.47 /(9.40+15+25+2.88+3.49)] \times 100=4 \%
$$

where 2.47 is the weight (in g) of paracetamol and 9.40, 15, 25, 2.88, and 3.49 are the weights (in g) of phenol, sodium nitrate, sulfuric acid, sodium borohydride, and acetic anhydride, respectively;

- Following Route 2 ( $\mathrm{N}$-acetylation with acetyl chloride)

$$
\text { overall } \mathrm{RME}_{\text {Curzons }}=[4.10 /(9.40+15+25+2.88+2.17)] \times 100=8 \%
$$

- $\quad$ Following Route 3 (Hoechst-Celanese process)

$$
\text { overall } \operatorname{RME}_{\text {Curzons }}=[10.33 /(9.40+12.0+7.32+4.82)] \times 100=31 \%
$$

Comparison between the values associated with Routes 1-3 clearly demonstrates the superiority of the Hoechst-Celanese process in terms of $\mathrm{RME}_{\text {Curzons }}$. This is explained by the excellent overall yield and the absence of entering reagent in the rearrangement step.

$\mathrm{RME}_{\text {Curzons }}$ and overall $\mathrm{RME}_{\text {Curzons }}$ values calculated for protocols reported in Sections 3.1-3.6 are gathered in Table 1 .

\subsubsection{Stoichiometric Factor}

The stoichiometric factor (SF) enables a comparison between an experimental process and a similar process in which all reactants should be used stoichiometrically [18]. Mention must be made that yield does not influence the value (in a similar way that it does not influence the value of the atom economy). The SF reflects the extent by which an excess of reagent(s) is used.

$$
\begin{aligned}
& \mathrm{SF}=1+[\text { (sum of the weights of the reactants-sum of the weights of the reactant in a } \\
& \text { stoichiometric process }) / \text { sum of the weights of the reactant in a stoichiometric process }] \text {. }
\end{aligned}
$$

For nitration of phenol, we have:

$$
\mathrm{SF}=1+\{[(15.0+25.0+9.4)-(8.5+9.8+9.4)] /(8.5+9.8+9.4)\}=1+0.7=1.07
$$

where $(15.0+25.0+9.4)$ represents the sum of the weights (in g) of, respectively, sodium nitrate, sulfuric acid, and phenol used in the reaction and $(8.5+9.8+9.4)$ the sum of the weights (in g) of the same reagents used in a stoichiometric manner $(100 \mathrm{mmol})$. The value of 1.07 indicates that $7 \%$ of the weight of the reagents are used in excess in the reaction. There is no link between that value and atom economy, yield or amount of waste.

An overall stoichiometric factor [19] is calculated in a similar way considering the limiting reagent in the first step. Thus, for the preparation of paracetamol following Route 1 (Figure 4) and acetylation with diluted acetic anhydride (Section 3.3.1), we find:

$$
\begin{gathered}
\mathrm{SF}=1+\{[(15.0+25.0+9.4+7.75+12.75)-(8.5+9.8+9.4+3.8+10.2)] /(8.5+9.8+ \\
9.4+3.8+10.2)=1+0.66=1.66 .
\end{gathered}
$$

In that overall sequence, $66 \%$ of the weights of the reagents were used in excess.

SF and overall SF values calculated for protocols reported in Sections 3.1-3.6 are gathered in Table 1. 


\subsection{When Reactants, Product(s), As Well As Solvents and Any Additional Substance Are Considered}

\subsubsection{Global Reaction Mass Efficiency and Effective Mass Yield}

Global reaction mass efficiency (gRME) [19,20], seldom referred to as mass productivity (MP) [20], corresponds to a mass balance for the chemical process in its entirety. It is the ratio between the isolated weight of the final product and the sum of the weights of all materials entering in the reaction, including solvents, drying agents, washing solutions, and any other compound implemented during the experiment [21]:

$\mathrm{gRME}=$ isolated weight of the desired product/sum of weights introduced in the process

Generally, water is excluded from the calculation but it can be included; this remains a subject of controversies [21]. For nitration of phenol, when the weight of water is included, the value is

$$
\operatorname{gRME}=5.14 /(15+40+25+9.40+25+25)=0.04
$$

where $5.14 \mathrm{~g}$ represents the weight of 4-nitrophenol, 15, 25, and $9.40 \mathrm{~g}$ the weight of, respectively, sodium nitrate, sulfuric acid, and phenol; it is assumed that approximately $90 \mathrm{~g}$ of water is required in the protocol.

gRME and overall gRME values calculated for protocols reported in Sections 3.1-3.6 are gathered in Table 1. From the data, it clearly appears that, except for the individual reactions of acetylation under solvent-free conditions (Sections 3.3.3 and 3.3.4), all gRME values are below 10\%. That means that more than $90 \%$ of the weight of the substances involved in the reactions were not incorporated in the final products and thus generated waste, if not recycled.

In green chemistry, the idea of effective mass yield (EMY) is also encountered [22]. The definition is similar to that of RME but only non-benign reactants are considered in the denominator. Many authors underline that the definition of non-benign material is not necessarily straightforward and some confusion can arise [23].

Table 1. Metrics associated with protocols considered for the preparation of paracetamol.

\begin{tabular}{|c|c|c|c|c|c|}
\hline & AE (\%) & Yield (\%) & RME $_{\text {Curzons }}(\%)$ & SF & gRME (\%) \\
\hline \multicolumn{6}{|l|}{ Route 1} \\
\hline Nitration of phenol & 50 & 37 & 10 & 1.79 & 4 \\
\hline Reduction & 62 & 74 & 37 & 1.22 & 2 \\
\hline Acetylation $\left(\right.$ dil. $\left.\mathrm{Ac}_{2} \mathrm{O}\right)$ & 72 & 60 & 38 & 1.12 & 7 \\
\hline Overall (dil. $\left.\mathrm{Ac}_{2} \mathrm{O}\right)$ & 36 & 16 & 4 & 1.67 & 1 \\
\hline Acetylation (pure $\mathrm{Ac}_{2} \mathrm{O}$, cat.) & 72 & 91 & 23 & 1.92 & 4 \\
\hline Overall (pure $\mathrm{Ac}_{2} \mathrm{O}$, cat.) & 36 & 25 & 6 & 2.08 & 1 \\
\hline Acetylation (pure $\mathrm{Ac}_{2} \mathrm{O}$ ) & 72 & 97 & 69 & 1.01 & 69 \\
\hline Overall (pure $\mathrm{Ac}_{2} \mathrm{O}$ ) & 36 & 27 & 7 & 1.61 & 2 \\
\hline \multicolumn{6}{|l|}{ Route 2} \\
\hline Acetylation $(\mathrm{AcCl})$ & 81 & 99 & 79 & 1.01 & 79 \\
\hline Overall $(\mathrm{AcCl})$ & 38 & 27 & 8 & 1.64 & 2 \\
\hline \multicolumn{6}{|l|}{ Route 3} \\
\hline Acetylation of phenol & 88 & 96 & 61 & 1.39 & 6 \\
\hline Oximation & 63 & 99 & 58 & 1.09 & 8 \\
\hline Rearrangement & 100 & 71 & 71 & 1.00 & 5 \\
\hline Overall & 58 & 68 & 31 & 1.32 & 2 \\
\hline
\end{tabular}

\subsubsection{Process Mass Intensity and E Factor}

Process mass intensity (PMI) is calculated as the inverse of the global RME [15,18]. Thus:

$$
\mathrm{PMI}=1 / \mathrm{gRME}
$$


or

PMI = sum of the weights introduced in the process/isolated weight of the desired product.

Notice that RME varies from nearly 0 to 1 for an ideal process, whereas PMI ranges from 1 for an ideal process to higher values for less efficient cases. For the nitration of phenol, we find:

$$
\mathrm{PMI}=1 / 0.04=25
$$

It is obvious that considering the amount of water in the process has a dramatic impact on the value. Indeed, when water is not taken into account, PMI drops to 9.6.

The E factor [24], where E stands for "environment", is the ratio between the weights of everything used during the transformation but not incorporated in the desired product and the isolated weight of the desired product:

$$
\text { E factor = weight of waste/isolated weight of the desired product. }
$$

Process mass intensity (PMI) and E factor are linked by the relation:

$$
\mathrm{PMI}=\mathrm{E} \text { factor }+1
$$

Following Sheldon [15], E factors (kg of waste/ $\mathrm{kg}$ of products) range from 0.1 for oil refining to values higher than 25 in the pharmaceutical sector. The author favors use of the E factor metric because in an ideal process E factor is 0, whereas PMI is 1. Let us, however, underline that experimentally it is more difficult to determine the amount of waste in a process (required to calculate $E$ factor) than the amount of entering materials (required to calculate PMI).

\section{The EcoScale}

When a more exhaustive determination of the greenness of a chemical reaction is required, many other factors than mass balances should be considered. Among them, let us mention energy balances, which include calculations of the energy used to perform the reaction itself (Joule $/ \mathrm{kg}$ of product) but also calculations of the energy used to extract or prepare and to recycle or destruct reagents, solvents, or auxiliaries. Prices, ease and safety of handling, renewability, atmospheric emissions, and environmental risks must also be taken in account, not only in the case of the reaction itself but again in steps preceding and following it. Therefore, studies "from cradle to grave" must be conducted i.e., "life cycle analyses" (LCA) [25-27], whose principles and framework can be found in the ISO 14040:2006 document [28]. It is not easy to perform such life cycle analyses so we would like to point out the existence of a highly simplified but indicative approach that has been developed by Van Aken et al. [29] in 2006. It is a semi-quantitative tool that comprises six parameters characterizing a reaction: yield, prices of the components, safety, technical set-up, temperature and time, work-up and purification. Within each of these parameters, individual penalty points are associated to particular situations, which are described in Table 2. The ideal score is attributed to an ideal reaction in which a compound A (substrate) undergoes a reaction with (or in the presence of) inexpensive compounds B to give the desired product $C$ in $100 \%$ yield at room temperature with a minimal risk for the operator and a minimal impact for the environment. The actual EcoScale score is then calculated by lowering the ideal score of 100 by those penalty points. A value higher than 75 characterizes an excellent process; between 75 and 50, the score corresponds to an acceptable process; and below 50 the process is not acceptable. An automatic calculator is available online [30]. Many discussions can arise because of the subjective weight of the penalties and the subjective nature of the situations encountered in the process. Nevertheless, the work of Van Aken et al. has the merit to exist and to provide a rapid tool of evaluation, which can, moreover, be adapted by anyone. In 2012, a modified version has been proposed by Dash et al. [31] from Boehringer Ingelheim Pharmaceuticals company.

Penalty points and overall EcoScale scores calculated for Routes 1-3 are gathered in Table 3. 
Table 2. Penalty points used in the EcoScale.

\begin{tabular}{|c|c|}
\hline Parameters & Penalty Points \\
\hline Yield & $(100-$ Effective Yield $) / 2$ \\
\hline \multicolumn{2}{|l|}{ Price of the reaction components (to obtain $10 \mathrm{mmol}$ ) } \\
\hline Inexpensive $(<10$ US\$) & 0 \\
\hline Expensive (between 10 and 50 US\$) & 3 \\
\hline Very expensive (> 50 US\$) & 5 \\
\hline \multicolumn{2}{|l|}{$\begin{array}{l}\text { Safety (adapted for the Globally Harmonized System of } \\
\text { Classification and Labeling of Chemicals) }\end{array}$} \\
\hline GHS09 (dangerous for the environment) & 5 \\
\hline GHS06 (toxic) & 5 \\
\hline GHS02 (flammable) & 5 \\
\hline GHS01 (explosive) & 10 \\
\hline GHS07, GHS08 (extremely toxic) & 10 \\
\hline \multicolumn{2}{|l|}{ Technical setup } \\
\hline Common setup & 0 \\
\hline Instruments for controlled addition (dropping funnel, etc.) & 1 \\
\hline Unconventional activation technique (microwave, etc.) & 2 \\
\hline Pressure equipment $>1 \mathrm{~atm}$ & 3 \\
\hline Any additional special glassware & 1 \\
\hline (Inert) gas atmosphere & 1 \\
\hline Glove box & 3 \\
\hline \multicolumn{2}{|l|}{ Temperature/Time } \\
\hline Room temperature, $<1 \mathrm{~h}$ & 0 \\
\hline Room temperature, $<24 \mathrm{~h}$ & 1 \\
\hline Heating $<1 \mathrm{~h}$ & 2 \\
\hline Heating $>1 \mathrm{~h}$ & 3 \\
\hline Cooling to $0^{\circ} \mathrm{C}$ & 4 \\
\hline Cooling $<0{ }^{\circ} \mathrm{C}$ & 5 \\
\hline \multicolumn{2}{|l|}{ Workup/Purification } \\
\hline None & 0 \\
\hline Cooling to room temperature & 0 \\
\hline Adding solvent & 0 \\
\hline Simple filtration & 0 \\
\hline Removal of solvent with $\mathrm{bp}<150^{\circ} \mathrm{C}$ & 0 \\
\hline Crystallization and filtration & 1 \\
\hline Removal of solvent with $\mathrm{bp}>150^{\circ} \mathrm{C}$ & 2 \\
\hline Solid phase extraction & 2 \\
\hline Distillation & 3 \\
\hline Sublimation & 3 \\
\hline Liquid-liquid extraction & 3 \\
\hline Classical chromatography & 10 \\
\hline
\end{tabular}

Values collected in Table 3 demonstrate that safety plays a dramatic role in the evaluation of the performances of the various protocols affording paracetamol. Amazingly, whereas the Hoechst-Celanese process emerged as a performing procedure when mass balances only were considered, that process requires as many experimental precautions as the two other synthetic routes. Temperature conditions, essentially cooling, are additional factors rendering Route 3 less environmentally friendly than expected from, for example, estimation of the atom economy. 
Table 3. Penalty points and overall EcoScale scores for the preparation of paracetamol.

\begin{tabular}{|c|c|c|c|c|c|}
\hline \multirow[b]{2}{*}{ Parameters } & \multicolumn{5}{|c|}{ Penalty Points for Route } \\
\hline & $\begin{array}{l}\text { 1, Acetylation } \\
\text { with dil. } \mathrm{Ac}_{2} \mathrm{O}\end{array}$ & $\begin{array}{l}\text { 1, Acetylation with } \\
\text { Pure } \mathrm{Ac}_{2} \mathrm{O} \text { and Cat. }\end{array}$ & $\begin{array}{l}\text { 1, Acetylation } \\
\text { with Pure Ac2O }\end{array}$ & 2 & 3 \\
\hline $\begin{array}{l}\text { Yield } \\
\text { Safety }\end{array}$ & $42.0(37 \%)$ & $37.5(25 \%)$ & $36.5(27 \%)$ & $36.5(27 \%)$ & $16(68 \%)$ \\
\hline Reagents $^{\text {a }}$ & 45 & 45 & 45 & 50 & 60 \\
\hline Intermediates ${ }^{b}$ & 50 & 50 & 50 & 50 & 20 \\
\hline Solvents, auxiliaries ${ }^{c}$ & 30 & 30 & 30 & 30 & 50 \\
\hline Technical setup & 1 & 1 & 3 & 3 & 4 \\
\hline Temperature/Time & 8 & 8 & 8 & 8 & 14 \\
\hline Workup/Purification & 6 & 6 & 6 & 6 & 6 \\
\hline $\begin{array}{l}\text { Overall EcoScale scores } \\
\text { (excluding safety) }\end{array}$ & 43.0 & 47.5 & 46.5 & 46.5 & 60.0 \\
\hline
\end{tabular}

a Phenol (GHS05, GHS08); sulfuric acid (GHS05); sodium nitrate (GHS07); sodium borohydride (GHS02, GHS06); acetic anhydride (GHS02, GHSO6); acetyl chloride (GHS02, GHS07); acetic acid (GHS02); hydroxylamine hydrochloride (GHS07, GHS08, GHS09); $\mathrm{NH}_{4} \mathrm{OH}$ (GHS07, GHS09); ${ }^{\text {b }}$ 4-Nitrophenol (GHS05, GHS08); 2-nitrophenol (GHS07); 4-aminophenol (GHS07, GHS08, GHS09); 4'-hydroxyacetophenone (GHS07); 4'-hydroxyacetophenone oxime (GHS07); ${ }^{c} \mathrm{Pd} / \mathrm{C}$ (GHS07); $\mathrm{HCl}$ (GHS07); $\mathrm{NaHCO}_{3}$ (GHS07); $\mathrm{HF}$ (GHS06); $\mathrm{KOH}$ (GHS07); $\mathrm{C}_{2} \mathrm{H}_{5} \mathrm{OH}$ (GHS02, GHS 07, GHS 08); trifluoroacetic acid (GHS07).

\section{The Radial Polygon Representation}

Values collected in Tables 1 and 3 can readily be inserted in radial polygons $[17,32,33]$ in which each summit would represent a value of $100 \%$ and the center a value of $0 \%$; note that $100 / \mathrm{SF}$ rather than $\mathrm{SF}$ is used in those representations. Although pentagons are often preferred for that purpose, we chose the hexagon by assigning one summit to the EcoScale value (excluding the penalty points for safety). The summits of the polygon correspond to the ideal process, whereas joining the coordinates on the radius will give a distorted polygon depicting the actual procedure, as illustrated in Figure 5. Distortions will help the chemist to identify parameters that must be improved in order to perform a more efficient and consequently a more environmentally friendly synthesis. Examination of Figure 5 reveals that Route 3 constitutes a reasonable synthetic sequence when compared with Routes 1 and 2. However, reaction mass efficiency as defined by Curzons should be increased. This could be accomplished by: (i) reducing the excess of acetylating agent (two-fold excess of acetic acid); (ii) using commercially available hydroxylamine (rather than the hydrochloride salt that must be neutralized); and (iii) improving the yield of the Beckmann rearrangement step. It is noteworthy that all of the protocols we considered, including Route 3, are characterized by extremely deplorable global reaction mass efficiency and penalty points for safety. Global RME could be modified by adjusting the volumes of solvents used in the workup procedures. Safety, as defined in the EcoScale, could hardly be modified because it is determined by the nature of the reagents and all auxiliary substances involved in the reactions. 

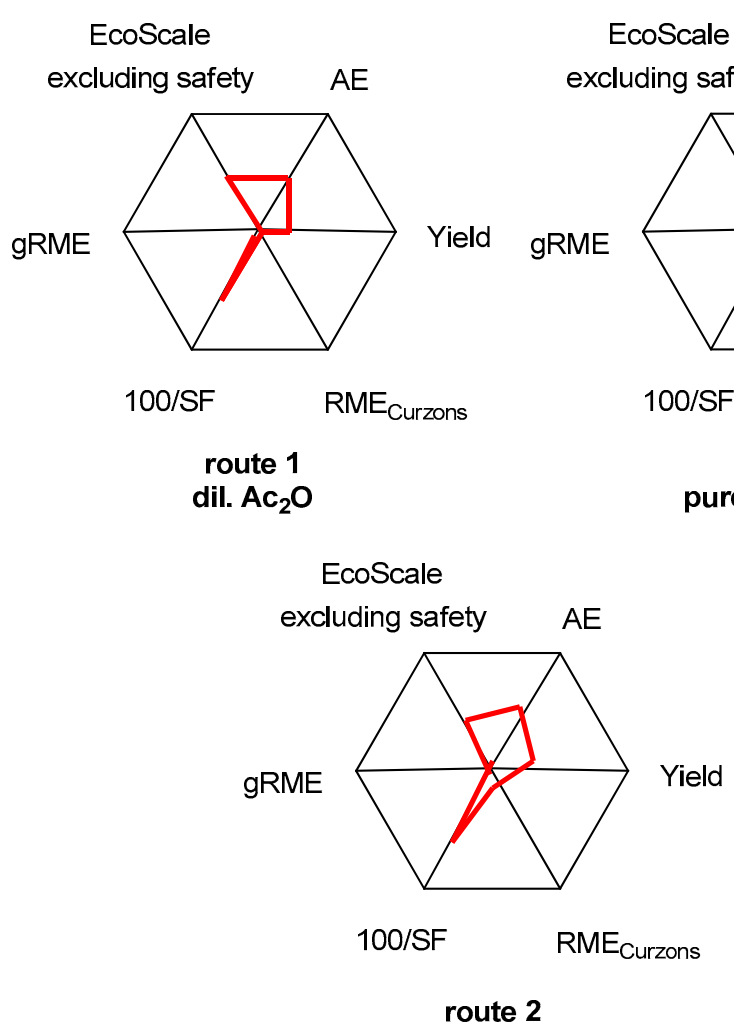
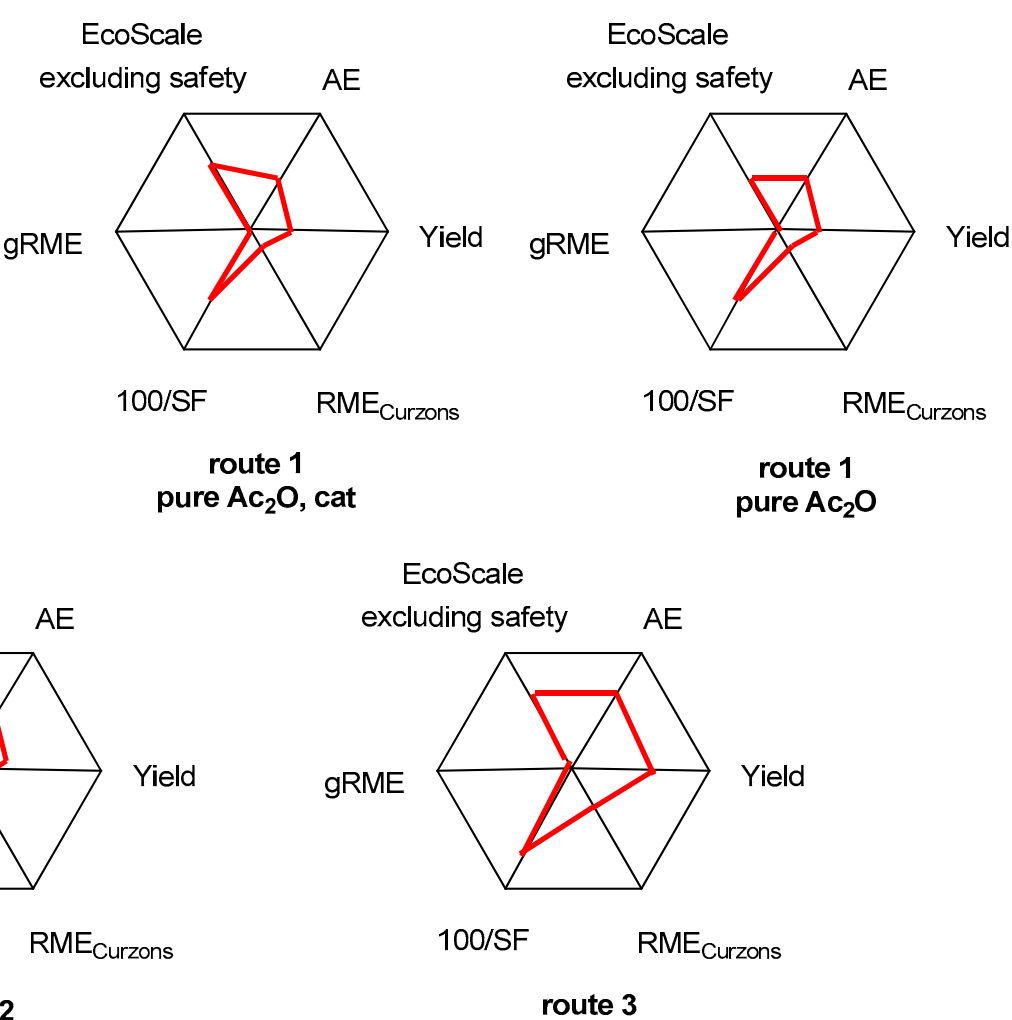

Figure 5. The radial hexagon representations for the preparation of paracetamol, where $A E=$ atom economy, $\mathrm{SF}$ = stoichiometric factor, $\mathrm{RME}_{\text {Curzons }}=$ reaction mass efficiency following Curzons, and $\mathrm{gRME}=$ global reaction mass efficiency.

\section{Conclusions}

Because all of us are conscious that our environment must be protected and kept as clean as still possible, many efforts have been and are necessitated in order to prevent formation and accumulation of waste as well as emission of greenhouse gases. Chemists can take part in those challenges and there is no doubt that the birth of so-called "green chemistry" has already modified the ways researchers are conceiving chemical transformations. Actually, some quantitative tools are available to evaluate the efficiency of a reaction and to point out its weaknesses in terms of ecological, economical, and safety impacts. Some of those tools are described in this review and applied to the preparation of paracetamol following three different routes. Some chemists would claim that several individual steps constitute green reactions because, for example, they are performed in water or in the absence of solvent. However, when looking at metrics used in green chemistry, it clearly appears that the use of water as the solvent or even the absence of solvent have little influence on the overall performances of the chemical transformations yielding paracetamol.

There are numerous articles, reviews, and books dealing with green chemistry. A short and arbitrary selection can be found in references [34-47].

Conflicts of Interest: The author declares no conflict of interest.

\section{References}

1. Paris Agreement-European Commission. Available online: http://ec.europa.eu/clima/policies/ international/negotiations/paris/index_en.htm (accessed on 1 May 2016).

2. Anastas, P.T.; Warner, J.C. Green Chemistry: Theory and Practice; Oxford University Press: London, UK, 1998.

3. 20th Annual Green Chemistry and Engineering Conference. Available online: http://www.gcande.org/ (accessed on 1 May 2016). 
4. Anastas, P.T.; Zimmerman, J.B. Design through the 12 principles of engineering. Environ. Sci. Technol. 2003, 37, 94A-101A. [CrossRef]

5. Abraham, M.A.; Nguyen, N. Green engineering: Defining the principles-Results from the Sandestin conference. Environ. Prog. 2003, 22, 233-206. [CrossRef]

6. Winterton, N. Twelve more green chemistry principles. Green Chem. 2001, 3, G73-G81.

7. Bogle, D.; Seaman, M. The six principles of sustainability. TCE Magazine, March 2010; 30-32.

8. Ellis, F. Paracetamol-A Curriculum Resource; Osborne, C., Pack, M., Eds.; Royal Society of Chemistry: London, UK, 2002.

9. Anantharaman, P.N. Paracetamol from phenol via para-nitrophenol. Bull. Electrochem. 1985, 1, 471.

10. Gharib, A.; Scheeren, J.H.W.; Bamoharram, F.F.; Roshani, M.; Jahangir, M. Acetylation of $p$-aminophenol by Preyssler's anion $\left[\mathrm{NaP}_{5} \mathrm{~W}_{30} \mathrm{O}_{110}\right]^{14-},\left[\mathrm{NaP}_{5} \mathrm{~W}_{29} \mathrm{MoO}_{110}\right]^{14-}$ with green condition at room temperature. Pol. J. Chem. Technol. 2009, 11, 31-35. [CrossRef]

11. Amin, M.; Iqbal, M.S. Solvent-free Synthesis of Acetaminophen. US Patent 9006488, 14 Apirl 2015.

12. Davenport, K.G.; Hilton, C.B. Process for Producing N-acyl-hydroxy Aromatic Amines. US Patent 4524217, 18 June 1985.

13. Fritch, J.R.; Fruchey, S.O.; Horlenko, T.; Aguilar, D.A.; Hilton, C.B.; Snyder, P.S.; Seeliger, W.J. Production of Acetaminophen. US Patent 5155273, 13 October 1992.

14. Trost, B.M. The atom economy-A search for synthetic efficiency. Science 1991, 254, 1471-1477. [CrossRef] [PubMed]

15. Sheldon, R.A. Organic Synthesis-Past, present and future. Chemistry and Industry: London, UK, 1992; pp. 903-906.

16. Curzons, A.D.; Constable, D.J.C.; Mortimer, D.N.; Cunningham, V.L. So you think your process is green, how do you know?-Using principles of sustainability to determine what is green-A corporate perspective. Green Chem. 2001, 3, 1-6. [CrossRef]

17. Dicks, A.P.; Hent, A. Atom economy and reaction mass efficiency. In Green Chemistry Metrics. A Guide to Determining and Evaluating Process Greenness; Springer: Heidelberg, Germany, 2015.

18. Andraos, J. Unification of reaction metrics for green chemistry: Application to reaction analysis. Org. Process Res. Dev. 2005, 9, 149-163. [CrossRef]

19. Andraos, J.; Hent, A. Simplified application of material efficiency green metrics to synthesis plans: Pedagogical case studies selected from Organic Synthesis. J. Chem. Educ. 2015, 92, 1820-1830. [CrossRef]

20. Constable, D.J.C.; Curzons, A.D.; Cunningham, V.L. Metrics to "green" chemistry-Which are the best? Green Chem. 2002, 4, 521-527. [CrossRef]

21. Dunn, P.J. The Importance of Green Chemistry in process Research \& Development. In Pharmaceutical Process Development-Current Chemical and Engineering Challenges; Blacker, A.J., Williams, M.T., Eds.; RSC Publications: Cambrige, UK, 2011; pp. 117-137.

22. Hudlicky, T.; Frey, D.A.; Koroniak, L.; Claeboe, C.D.; Brammer, L.E., Jr. Toward a reagent free synthesis. Green Chem. 1999, 1, 57-59. [CrossRef]

23. Centi, G.; Perathoner, S. Accounting for Chemical Sustainability. In Sustainable Industrial Chemistry: Principles, Tools and Industrial Examples; Cavani, F., Centi, G., Perathoner, S., Trifiro, G., Eds.; Wiley-VCH: Weinheim, Germany, 2009; pp. 279-318.

24. Sheldon, R.A. The E factor: Fifteen years on. Green Chem. 2007, 9, 1273-1283. [CrossRef]

25. Avres, R.U. Life cycle analysis: A critique. Resour. Conserv. Recyl. 1995, 14, 199-223. [CrossRef]

26. Anastas, P.T.; Lankey, R.L. Life cycle assessment and green chemistry: The yin and yang of industrial ecology. Green Chem. 2000, 2, 289-295. [CrossRef]

27. Cespi, D.; Beach, E.S.; Swarr, T.E.; Passarini, F.; Vassura, I.; Dunn, P.J.; Anastas, P.T. Life cycle inventory improvement in the pharmaceutical sector: Assessment of the sustainability combining PMI and LCA tools. Green Chem. 2015, 17, 3390-3400. [CrossRef]

28. ISO 14040:2006(en). Environmental management-Life cycle assessment-Principles and framework. Available online: https://www.iso.org/obp/ui/\#iso:std:iso:14040:ed-2:v1:en (accessed on 1 May 2016).

29. Van Aken, K.; Strekowski, L.; Patiny, L. EcoScale, a semi-quantitative tool to select an organic preparation based on economical and ecological parameters. Beilstein J. Org. Chem. 2006, 2. [CrossRef] [PubMed]

30. Ecoscale.org. 2016. Available online: www.ecoscale.org (accessed on 1 May 2016). 
31. Dash, R.; Song, J.J.; Roschangar, F.; Samstag, W.; Senanayake, C.H. The eight criteria defining a good manufacturing process. Org. Process Res. Dev. 2012, 16, 1697-1706.

32. Andraos, J.; Sayed, M. On the use of "green" metrics in the undergraduate organic chemistry lecture and lab to assess the mass efficiency of organic reactions. J. Chem. Educ. 2007, 84, 1004-1010. [CrossRef]

33. Andraos, J. Inclusion of environmental impact parameters in radial pentagon material efficiency metrics analysis: Using benign indices as a step towards a complete assessment of "greenness" for chemical reactions and synthesis plans. Org. Process Res. Dev. 2012, 16, 1482-1506. [CrossRef]

34. Lapkin, A.; Constable, D.C. Green Chemistry Metrics: Measuring and Monitoring Sustainable Processes; John Wiley \& Sons, Ltd: Chichester, UK, 2008.

35. Calvos-Flores, F.G. Sustainable chemistry metrics. ChemSusChem 2009, 2, 905-919. [CrossRef] [PubMed]

36. Dunn, P.J.; Wells, A.S.; William, M.T. Green Chemistry in the Pharmaceutical Industry; Wiley-VCH Verlag GmbH \& Co. KGaA: Weinheim, Germany, 2010.

37. Lancaster, M. Green Chemistry: An Introductory Text, 2nd ed.; RSC Publishing: Cambridge, UK, 2010.

38. Jimenez-Gonzalez, C.; Poechlauer, P.; Broxterman, Q.B.; Yang, B.-S.; Ende, D.A.; Baird, J.; Bertsch, C.; Hannah, R.E.; Dell'Orco, P.; Noorman, H.; et al. Key green engineering research areas for sustainable manufacturing: A perspective from pharmaceutical and fine chemicals manufacturers. Org. Process Res. Dev. 2011, 15, 900-911. [CrossRef]

39. Jimenez-Gonzalez, C.; Ponder, C.S.; Broxterman, Q.B.; Manley, J.B. Using the right green yardstick: Why process mass intensity is used in the pharmaceutical industry do drive more sustainable processes. Org. Process Res. Dev. 2011, 15, 912-917. [CrossRef]

40. Mercer, S.M.; Andraos, J.; Jessop, P.G. Choosing the greenest synthesis: A multivariate metric green chemistry exercise. J. Chem. Educ. 2012, 89, 215-220. [CrossRef]

41. Andraos, J. The Algebra of Organic Synthesis: Green Metrics, Design Strategy, Route Selection, and Optimization; CRC Press: Boca Raton, FL, USA, 2012.

42. Ribeiro, M.G.T.C.; Machado, A.A.S.C. Greenness of chemical reactions -limitations of mass metrics. Green Chem. Lett. Rev. 2013, 6, 1-18. [CrossRef]

43. Baird, C.; Cann, M. Environmental Chemistry, 5th ed.; Edition, W.H., Ed.; Freeman and Co: New York, NY, USA, 2012.

44. Anastas, P.T.; Zimmerman, J.B. Innovations in Green Chemistry and Green Engineering: Selected Entries from the Encyclopedia of Sustainability Science and Technology; Springer: New York, NY, USA, 2013.

45. Koenig, S.G. Scalable Green Chemistry: Case Studies from the Pharmaceutical Industry; CRC Press Taylor and Francis Group: Boca Raton, FL, USA, 2013.

46. Toniolo, S.; Arico, F.; Tundo, P. A comparative environmental assessment for the synthesis of 1,3-oxazin-2-one by metrics: greenness evaluation and blind spots. ACS Sustain. Chem. Eng. 2014, 2, 1056-1062. [CrossRef]

47. Albini, A.; Protti, S. Paradigms in Green Chemistry and Technology; Springer Verlag GmbH: Berlin, Germany, 2016.

(C) 2016 by the author; licensee MDPI, Basel, Switzerland. This article is an open access article distributed under the terms and conditions of the Creative Commons Attribution (CC-BY) license (http://creativecommons.org/licenses/by/4.0/). 